2016-02-09

\title{
Promoting the 3Rs to enhance the OECD fish toxicity testing framework.
}

\author{
Hutchinson, $\mathrm{TH}$
}

http://hdl.handle.net/10026.1/5256

10.1016/j.yrtph.2016.02.006

Regulatory toxicology and pharmacology : RTP

All content in PEARL is protected by copyright law. Author manuscripts are made available in accordance with publisher policies. Please cite only the published version using the details provided on the item record or document. In the absence of an open licence (e.g. Creative Commons), permissions for further reuse of content should be sought from the publisher or author. 
3 Commentary:

\section{Promoting the 3Rs to enhance the OECD Fish Toxicity}

\section{Testing Framework.}

6

7 Thomas H. Hutchinson $\dagger^{*}$, James R. Wheeler

8

$9 †$ School of Biological Sciences, University of Plymouth, Drake Circus, Plymouth PL4 8AA,

10 United Kingdom; email tom.hutchinson@plymouth.ac.uk

\$Dow AgroSciences, 3B Park Square, Milton Park, Abingdon, Oxfordshire OX14 4RN,

13 United Kingdom; email jrwheeler@dow.com

14

15 \# Organization for Economic Co-operation and Development (OECD), 2 rue André-Pascal, $16 \quad$ F-75775 Paris Cedex 16, France; email anne.gourmelon@oecd.org

§NC3Rs, Gibbs Building, 215 Euston Road, London NW1 2BE, United Kingdom. Email natalie.burden@nc3rs.org.uk 584605; Email tom.hutchinson@plymouth.ac.uk. 
24 Fish testing has been used to understand chemical and effluent toxicity since the 1860's and continues to play an important role towards defining safe levels of chemical contaminants in lakes, rivers and coastal waters (Sprague 1971; Hunn 1989). Historically, many severe chemical pollution problems led to fish kills giving rise to a focus on acute lethality testing of chemicals and effluents. More recently, the focus of concern is on long term effects of chemicals directly on fish and also indirectly via impacts on invertebrate prey species and other taxa. Consequently, fish toxicity testing is embedded in most regulatory programmes for prospective and retrospective assessment of individual chemical substances and effluents. Current regulations implementing environment protection (e.g. REACh and Plant Protection Products legislation) increasingly incorporate the wider societal view that vertebrate animal use should be Replaced, Reduced and Refined (the 3Rs) where possible. Such a paradigm shift also supports scientific and business needs to consider the 3Rs. The OECD Fish Toxicity Testing Framework (OECD 2012) provides a useful structure with which to simultaneously address the needs of high levels of environmental protection whilst implementing the 3Rs. This commentary aims to encourage awareness of this activity and promote the implementation of the recommendations of the OECD Fish Toxicity Testing Framework.

The historic need to be identify and prevent chemical impacts on fisheries and water quality led in 1981 to the Organisation for Economic Co-operation and Development (OECD) adopting the Fish Acute Toxicity Test Guideline 203 (updated in 1984 and 1992). Subsequently the Fish Early-Life Stage Toxicity Test Guideline 210 was adopted in 1988 (since updated in 2013). As scientific knowledge of the environmental risks posed by diverse chemicals has grown, the OECD has adopted a growing number of fish test guidelines to address bioconcentration, development and reproduction in fish. Today's OECD 'toolbox' of 
test guidelines plays a central role in supporting an internationally consistent approach to the environmental safety assessment of chemicals. We define the environmental safety assessment of chemicals as the evaluation of the predicted environmental exposure of a chemical with the predicted in vivo biological effect of the chemical, supported by mechanistic in silico and in vitro data describing the intrinsic (eco)toxicological properties or mode-of-action (MOA) of the chemical. In contrast, the environmental risk assessment of chemicals typically focusses solely on comparing the predicted exposure concentration (PEC) to the predicted no effect concentration (PNEC) derived from in vivo experiments for relevant taxonomic groups (fish, aquatic invertebrates and algae) in the absence of MOA data. Though perhaps a subtle distinction, the safety assessment approach offers scope for a more comprehensive use of all in silico, in vitro and in vivo information at multiple levels of biological organisation. Balancing the need for high standards of environmental protection with the demands and desire to implement the $3 \mathrm{Rs}$ is one of the key challenges for environmental safety assessment today. As part of addressing this challenge, the OECD (2012) developed the Fish Toxicity Testing Framework in order to provide guidance on how best to deploy the various fish toxicity and bioconcentration test guidelines, including consideration of the 3Rs. In our view, the OECD's Fish Toxicity Testing Framework provides a logical and transparent approach to this complex aspect of environmental safety assessment. A simplified version of the OECD Fish Toxicity Testing Framework is shown in Figure 1 (see OECD (2012) for full details). The OECD (2012) also considered a number of important outstanding questions of scientific and regulatory concerns, including for example, what are the options for reducing animal numbers in fish toxicity tests and how can less severe endpoints be given priority in decision making? 
73 More broadly, we believe there is reason to be optimistic that the 3 Rs can be successfully rich invertebrates (ECETOC 2007). applied to the OECD Fish Toxicity Testing Framework to support environmental safety assessment. Firstly, in terms of replacement, Figure 1 summarises some key opportunities and gives priority to the replacement of in vivo fish testing, where feasible, through the use of validated in silico and in vitro tools. However, these can only be applied with confidence within the chemical domains of the data used for their validation. Replacement of fish acute tests by the Fish Embryo Acute Toxicity Test Guideline 236 (adopted July 2013) may be possible under some regulations. Replacement of fish toxicity testing with suitable invertebrates may also be useful. Replacement may take the form of establishing targeted threshold test levels for fish (determined by full invertebrate tests) or complete replacement but this needs to be justified scientifically by an understanding of the exposure relevant MOA of a chemical in order to derive robust environmental safety assessments. For example, a the this mechanistic approach could offer a positive way forward to address the replacement of fish with arthropod toxicity tests where there is a shared MOA (e.g. ion channel mediated neurotoxicity of pyrethroids) or other a priori knowledge of a particularly more sensitive taxonomic group of invertebrates. This would be in contrast to a very different mode-ofaction specific to vertebrates (e.g. receptor-mediated feminization of fish by steroidal oestrogens) (ECETOC 2007). The development of adverse outcome pathways, as strongly supported by the OECD, could in the future help to identify where cross-species extrapolation is appropriate based upon a common Molecular Initiating Event (Ankley et al., 2010; Burden et al. 2015a; OECD (2015)). Invertebrates may also provide an environmentally relevant alternative bioconcentration test guideline given the potential for chemical uptake into lipid 
97 Secondly refinement of the severity of the experimental endpoints (i.e. degree of suffering induced) is another aspect of the OECD Fish Toxicity Testing Framework that warrants attention. For instance, minimising the assessment of lethality in fish and optimising the experimental design to focus on sublethal endpoints via the Maximum Tolerated

101 Concentration (MTC) approach (Hutchinson et al., 2009) is one aspect of refinement 102 considered by the OECD (2012). The OECD (2012) also recommended introducing the term 103 'moribund' in the fish acute toxicity Test Guideline 203, which would represent a significant 104 refinement. Discussions are currently ongoing regarding this guideline revision. Test 105 Guideline 204 (Fish, Prolonged Toxicity Test: 14-Day Study) was deleted after it was 106 deemed as 'ethically indefensible' and concerns have also been raised about the lack of 107 feeding in the Test Guideline 212 (Fish, Short-term Toxicity Test on Embryo and Sac-Fry 108 Stages).

110 Thirdly, further effort is needed to reduce the numbers of fish toxicity tests through a variety 111 of approaches. As summarized in OECD (2012), these approaches include moving away 112 from automatic 'tick box' testing to more efficient tiered testing frameworks and 'intelligent' 113 or 'integrated testing strategies' which make better use of in silico, in vitro and in vivo 114 information. However, operating such a flexible approach will undoubtedly result in greater 115 regulatory complexity. Further, work to explore the application of test guideline validity 116 criteria was also recommended. This could determine which deviation(s) (or magnitude of the 117 deviation) from criteria fundamentally undermines study outcomes and overall test 118 performance (hence necessitating repeat studies), and conversely which do not impact on the 119 scientific quality of studies (thus negating the need for their repetition). 
121 The OECD framework is not comprehensive of all opportunities to address the 3Rs as 122 described elsewhere. However, it offers tangible opportunities to address the issues with what 123 constitutes the building blocks of the current regulatory data requirements (i.e. test guideline 124 studies mandated by the various chemical legislations). As such it fits with the current legal 125 frameworks and so offers an ability to improve 3Rs application in the short and medium 126 terms whilst fundamentally different approaches are developed and mature sufficiently for 127 regulatory implementation (Burden et al. 2015b). A number of the OECD Fish Toxicity 128 Testing Framework recommendations have already developed as projects and made it on to 129 the OECD's work plan (see Table 1).

130

131 In conclusion, the OECD (2012) generic framework provides a highly valuable opportunity to improve fish toxicity and bioconcentration testing. The OECD framework highlights key 3Rs opportunities that are consistent with the scientific and ethical principles increasingly 134 required by regulations, industry and society for chemical safety assessment. We encourage 135 international stakeholders to take up the recommendations from the OECD framework in 136 order to further promote the reduction, replacement and refinement of fish toxicity testing 137 within the environmental safety assessment context. 
References

141

142 Ankley, G.T., Bennett, R.S., Erickson, R.J., Hoff, D.J., Hornung, M.W., Johnson, R.D.,

143 Mount, D.R., Nichols, J.W., Russom, C.L., Schmieder, P.K., Serrrano, J.A., Tietge, J.E.,

144 Villeneuve, D.L., 2010. Adverse outcome pathways: a conceptual framework to support

145 ecotoxicology research and risk assessment. Environmental Toxicology and Chemistry 29:

$146 \quad 730-741$.

147

148 Burden, N., F. Sewell, M. E. Andersen, A. Boobis, J. K. Chipman, M. T. Cronin, T. H.

149 Hutchinson, I. Kimber and M. Whelan (2015). "Adverse Outcome Pathways can drive non-

150 animal approaches for safety assessment." J Appl Toxicol 35(9): 971-975.

151

152 Burden N, Benstead R, Clook M, Doyle I, Edwards P, Maynard SK, Ryder K, Sheahan D,

153 Whale G, van Egmond R, Wheeler JR, Hutchinson TH. 2015. Advancing the 3Rs in

154 regulatory ecotoxicology: A pragmatic cross-sector approach. Integrated environmental

155 assessment and management, 10.1002/ieam.1703. DOI: 10.1002/ieam.1703.

156

157 ECETOC (2007) Intelligent Testing Strategies in Ecotoxicology: Mode of Action Approach

158 for Specifically Acting Chemicals. ECETOC Technical Report 102. European Centre for

159 Ecotoxicology and Toxicology of Chemicals, Brussels, Belgium.

160 Hunn, J.B. (1989) History of acute toxicity tests with fish 1863-1987. US Department of the

161 Interior Fish \& Wildlife Service, LaCrosse, Wisconsin USA. Investigations in Fish Control

162 number 98, document reference I 49.70:98. 20 pp. 
163 Hutchinson T.H., Bögi C., Winter M.J., Owens J.W. 2009. Benefits of the Maximum

164 Tolerated Dose (MTD) and Maximum Tolerated Concentration (MTC) concept in aquatic 165 toxicology. Aquatic Toxicology 91: 197-202

166

167 OECD (2012) Fish Toxicity Testing Framework. OECD Series on Testing \& Assessment 168 number 171, document reference ENV/JM/MONO(2012)16. Organisation for Economic 169 Cooperation \& Development, 2 rue André-Pascal, Paris. 174pp

171 OECD (2015) Report of the Workshop on a Framework for the Development and Use Of

172 Integrated Approaches to Testing and Assessment. OECD Series on Testing \& Assessment 173 number 215, document reference ENV/JM/MONO(2015)22. Organisation for Economic 174 Cooperation \& Development, 2 rue André-Pascal, Paris. 154pp

175 Sprague, J.B. (1971) Measurement of pollutant toxicity to fish - III: sublethal effects and 176 'safe' concentrations. Water Research 5: 245-266 


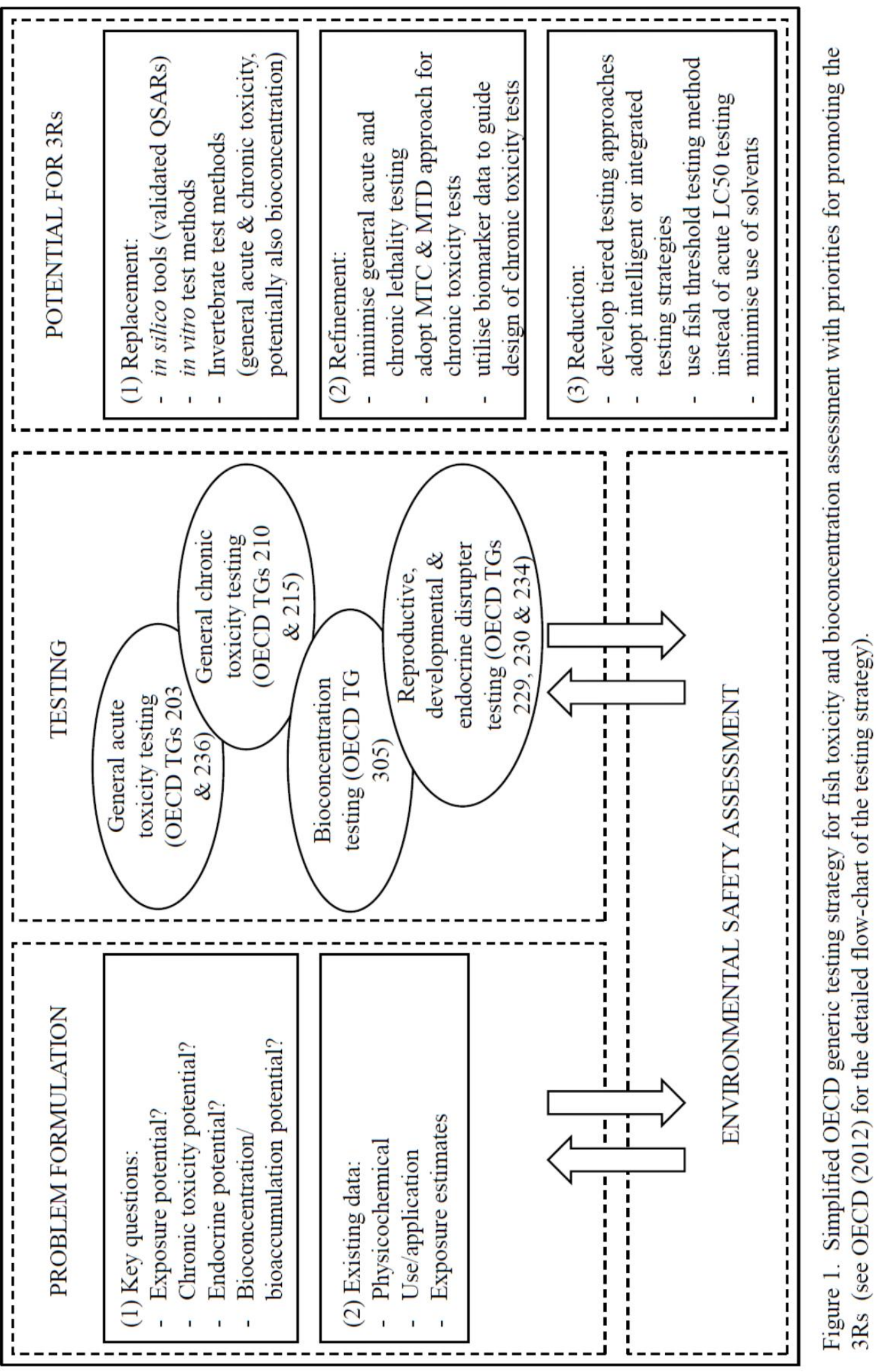


187 Table 1. Summary of OECD projects on (or proposed) the work plan associated with the 3Rs 188 in guideline ecotoxicity tests.

\begin{tabular}{|c|c|c|c|c|}
\hline $\begin{array}{l}\text { Project } \\
\text { Number }\end{array}$ & Title & $\begin{array}{l}\text { Date } \\
\text { included }\end{array}$ & $\begin{array}{l}\text { Lead } \\
\text { country }\end{array}$ & Issue \\
\hline 2.50 & $\begin{array}{l}\text { Revision of TG } \\
203 \text { Fish Acute } \\
\text { Toxicity Test }\end{array}$ & 2014 & $\begin{array}{l}\text { Switzerland/ } \\
\text { United } \\
\text { Kingdom }\end{array}$ & $\begin{array}{l}\text { Definition and implementation } \\
\text { of moribund to allow early of } \\
\text { termination of individuals to } \\
\text { prevent suffering (reliable } \\
\text { prediction of death) }\end{array}$ \\
\hline 2.54 & $\begin{array}{l}\text { Guidance } \\
\text { Document on } \\
\text { IATA for Fish } \\
\text { Acute Toxicity } \\
\text { Testing }\end{array}$ & 2015 & Austria & $\begin{array}{l}\text { Integrated Approaches to } \\
\text { Testing and Assessment for } \\
\text { acute fish toxicity testing }\end{array}$ \\
\hline 2.55 & $\begin{array}{l}\text { Use and analysis of } \\
\text { control fish in } \\
\text { toxicity studies }\end{array}$ & 2015 & $\begin{array}{l}\text { European } \\
\text { Commission }\end{array}$ & $\begin{array}{l}\text { Review and update of poorly } \\
\text { soluble substance guidance. } \\
\text { Detailed Review Paper of use } \\
\text { of controls in ecotoxicity tests }\end{array}$ \\
\hline Proposed & $\begin{array}{l}\text { Critical assessment } \\
\text { of deviations from } \\
\text { OECD Vertebrate } \\
\text { Ecotoxicology } \\
\text { Test Guidelines }\end{array}$ & 2016 & $\begin{array}{l}\text { United } \\
\text { Kingdom }\end{array}$ & $\begin{array}{l}\text { Review of test guideline } \\
\text { validity criteria. Update of test } \\
\text { guidelines and guidance on } \\
\text { interpretation to avoid } \\
\text { unnecessary repeats. }\end{array}$ \\
\hline
\end{tabular}

